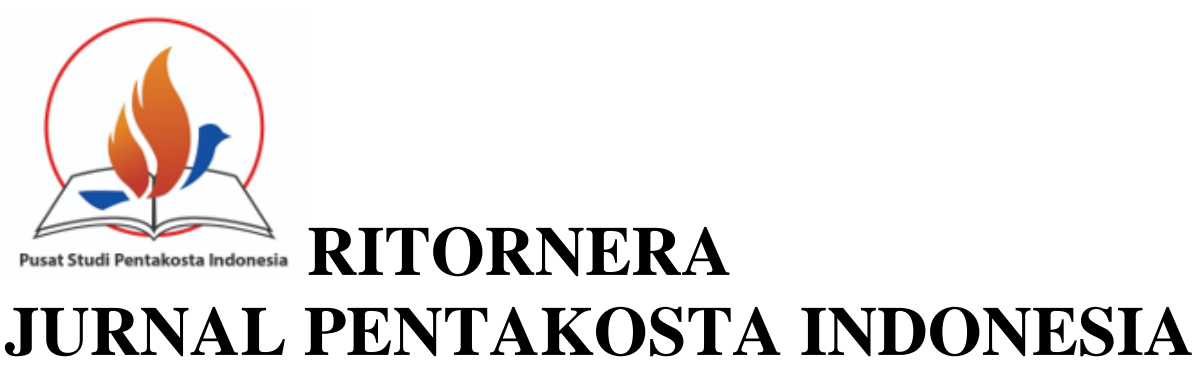

Vol. 1, No. 3, Desember 2021

Available at: pspindonesia.org

\title{
Membaca Ulang Kisah Natal dari Bingkai Spiritualitas Pentakosta
}

\author{
Kosma Manurung ${ }^{1}$ \\ kosmamanurung@sttintheos.ac.id
}

\begin{abstract}
Christmas is a celebration commemorating the birth of the Lord Jesus which in the Bible record is a story whose beginning was in God's plan long before the event itself occurred. By using a descriptive analysis approach and literature review, this research intends to offer a perspective on the Christmas story from the Pentecostal spirituality frame. This article contains several examples of the idea of Christmas in the Bible both in the Old Testament and reviews the first Christmas story in the New Testament and also the meaning of Christmas in the context of Pentecostal spirituality. It is concluded that Christmas is the fulfillment of God's promise, Christmas is about divine reconciliation, Christmas also talks about mission, and Christmas is God's means to restore the effects of sin.
\end{abstract}

Keywords: birth of Jesus; christmas; christmas celebration; divine mission; pentecostal spirituality; pentecostal theology

\begin{abstract}
Abstrak
Natal adalah sebuah perayaan memperingati kelahiran Tuhan Yesus yang dalam catatan Alkitab merupakan sebuah kisah yang permulaannya sudah ada dalam rencana Allah jauh sebelum peristiwa itu sendiri terjadi. Dengan menggunakan pendekatan deskriptif analisis dan kajian literatur penelitian ini bermaksud menawarkan sebuah sudut pandang tentang kisah natal dari bingkai spritualitas Pentakosta. Artikel ini berisikan beberapa contoh ide natal dalam Alkitab baik di Perjanjian Lama maupun ulasan kisah natal pertama di Perjanjian Baru dan juga arti natal dalam bingkai spritulitas Pentakosta. Disimpulkan bahwa natal adalah pengenapan janji Allah, natal berintikan tentang rekonisiali ilahi, natal juga berbicara tentang misi, dan natal menjadi sarana Allah untuk memulihkan dampak dosa.
\end{abstract}

Kata kunci : kelahiran Yesus; natal; perayaan natal; misi ilahi; spritualitas pentakosta; teologi pentakosta

\footnotetext{
${ }^{1}$ STT Intheos Surakarta
} 


\section{PENDAHULUAN}

Dunia yang manusia tinggali saat ini adalah dunia yang dipenuhi dengan berbagai keberagaman. ${ }^{1}$ Semisal ada begitu banyak jenis tumbuhan yang bisa ditemukan disatu daerah dan tidak bisa ditemukan didaerah lainnya atau ada hewan yang habitatnya hanya pada daerah tertentu dan tidak bisa ditemui didaerah lain. Belum lagi keberagaman dalam hal budaya yang membedakan satu daerah dengan daerah lain atau satu bangsa dengan bangsa lainnya. Di Nusantara saja ada budaya yang disatu daerah dianggap bagus malah didaerah lain dianggap tidak baik semisal menghabiskan minuman yang disediakan tamu, atau bersendawa. Namun, ada peristiwa atau perayaan tertentu yang sifatnya universal yang bisa ditemukan hampir disemua daerah atau negara, natal adalah contohnya. Pada masa kini perayaan natal tidak lagi dimonopoli oleh daerah-daerah yang mayoritas Kristen atau gereja saja, dari media elektronik orang percaya bisa melihat bahwa hiasan-hiasan natal bahkan memenuhi tempat umum, kantor pemerintahan, mall, bahkan di pusat kota bertebaran hiasan natal juga perayaan natal ini bisa ditemukan di negara-negara yang mayoritas beragama lain semisal negara Timur Tengah, Jepang, Cina dan lain sebagainya. ${ }^{2}$

Kisah natal adalah kisah kelahiran Tuhan Yesus yang juga bisa dimaknai sebagai kisah cinta Allah untuk umat manusia dan Allah membuktikan cinta-Nya dengan mengambil rupa seorang manusia, hidup ditengah ciptaan-Nya hanya dengan satu tujuan agar bisa menebus ciptaan-Nya dari hukuman kekal. ${ }^{3}$ Apa yang Tuhan sudah tunjukkan dan lakukan ini dibahasakan oleh Zaluchu sebagai sebagai tindakan cinta dari Tuhan untuk manusia yang memuncak pada pengorbanan-Nya di kayu salib. ${ }^{4}$ Menelusuri kisah natal tidak pernah terlepas dari apa yang dinyatakan oleh Alkitab yang diyakini oleh orang percaya sebagai pedoman hidup tertinggi yang mengatur segala sikap maupun perbuatan orang percaya

\footnotetext{
${ }^{1}$ Tony Salurante, Aprianus Moimau, and Filmon Berek, "Tujuan Penciptaan Sebagai Cara
} Memahami Keberagaman Etika Dalam Kekristenan,” Jurnal Teologi Berita Hidup 3, no. 2 (March 25, 2021): 120-136, accessed November 10, 2021, https:/e-journal.sttberitahidup.ac.id/index.php/jbh/article/view/91.

${ }^{2}$ Marselino Cristian Runturambi, "MAKNA TEOLOGI PERAYAAN NATAL YESUS KRISTUS," TUMOU TOU Jurnal Kristianitas, Ajaran, dan Kemasyarakatan VI, no. 1 (2019): 41-57, http://ejournaliakn-manado.ac.id/index.php/tumoutou/article/view/79.

${ }^{3}$ Elena M. Luludova, "Christmas and Christmastide in the Interpretation of Russian Writers of the XVIII-XX Centuries," Space and Culture, India 6, no. 4 (December 23, 2018): 93-101, accessed November 10, 2021, https://doi.org/10.20896/saci.v6i4.379.

${ }^{4}$ Sonny Zaluchu, "Penderitaan Kristus Sebagai Wujud Solidaritas Allah Kepada Manusia," DUNAMIS: Jurnal Penelitian Teologi dan Pendidikan Kristiani 2, no. 1 (November 4, 2017): 61, accessed November 17, 2020, http://www.sttintheos.ac.id/e-journal/index.php/dunamis. 
dalam kehidupan baik dalam kaitan dengan perkara jasmaniah maupun yang bersifat rohani. ${ }^{5}$ Ide kelahiran Tuhan yang dirayakan sebagai hari natal saat ini sudah terlihat semenjak kejatuhan Adam dan Hawa di taman Eden, dimana dalam Allah berfirman bahwa keturunan perempuan itu akan meremukan kepala ular (Kej. 3:15).

Perjanjian Baru memulai kisahnya dengan kisah natal seperti yang digambarkan dalam Injil Matius terkati silsilah dan kisah kelahiran Tuhan Yesus pada awal tulisannya (Mat. 1). Donald Guthrie melihat bahwa ada ketertarikan besar pada jemaat awal atau orang Kristen mula-mula akan pengenapan nubuat Perjanjian Lama oleh Yesus Kristus dan kisah natal yang merupakan kisah kelahiran Tuhan Yesus adalah titik awal dimana nubuat Perjanjian Lama itu mulai digenapi. ${ }^{6}$ Arrington mewakili teolog Pentakosta menyatakan bahwa kaum Pentakosta adalah kaum Alkitab artinya mempercayai sepenuhnya apa yang Alkitab katakan. ${ }^{7}$ Pandangan ini juga disetujui oleh Daniel Sutoyo yang menyatakan bahwa kaum Pentakosta membangun keseharian hidup mereka dari pemahaman akan Alkitab. ${ }^{8}$ Evan Siahan juga meneliti bahwa ketekunan dalam mempelajari Alkitab adalah karakteristik dari kaum Pentakosta. ${ }^{9}$ Adapun maksud dari artikel ini ingin memberikan sudut pandang tentang kisah natal dari bingkai spritualitas Pentakosta.

\section{METODE}

Pertimbangan memilih metode kualitatif dengan pendekatan deskriptif analisis dan kajian literatur didasarkan pada pertimbangan efesiensi dan memudahkan peneliti dalam mengerjakan artikel ini juga pada aspek kecocokannya. Metode kualitatif secara dasariah cocok digunakan untuk mendapatkan pemahaman maupun kedalaman makna dari topik yang sedang peneliti bahas. ${ }^{10}$ Pendekatan deskriptif analisis peneliti gunakan dalam pembahasan Alkitab dan kisah natal. Dimana pendekatan ini digunakan untuk meneropong

\footnotetext{
${ }^{5}$ Kosma Manurung, “ALKITAB DAN HUBUNGAN PERTEMANAN KAJIAN TEOLOGI PENTAKOSTA MEMAKNAI HUBUNGAN PERTEMANAN DALAM ALKITAB,” VOX DEI: Jurnal Teologi dan Pastoral 2, no. 1 (June 30, 2021): 2723-2751, accessed July 8, 2021, https://jurnal.sttekumene.ac.id/index.php/VoxDei/article/view/35.

${ }^{6}$ Donald Guthrie, PENGANTAR PERJANJIAN BARU Volume 1 (Surabaya: Momentum, 2015), 13.

${ }^{7}$ French L. Arrington, DOKTRIN KRISTEN PERSPEKTIF PENTAKOSTA (Yogyakarta: ANDI Offset, 2020), 7.

${ }^{8}$ Daniel Sutoyo, “Analisis Historis Terhadap Teologi Gerakan Pentakostalisme,” DUNAMIS: Jurnal Teologi dan Pendidikan Kristiani 2, no. 2 (April 23, 2018): 167, accessed June 17, 2020, doi: https://doi.org/10.30648/dun.v2i2.171.

${ }^{9}$ Harls Evan R. Siahaan, "Karakteristik Pentakostalisme Menurut Kisah Para Rasul," DUNAMIS: Jurnal Penelitian Teologi dan Pendidikan Kristiani 2, no. 1 (November 4, 2017): 12, accessed June 17, 2020, doi: https://doi.org/10.30648/dun.v2i1.132.

${ }^{10}$ Sonny Eli Zaluchu, "Strategi Penelitian Kualitatif Dan Kuantitatif Di Dalam Penelitian Agama," Evangelikal: Jurnal Teologi Injili dan Pembinaan Warga Jemaat 4, no. 1 (2020): 28-38.
}

Copyright(C2021; Ritornera - Jurnal Teologi Pentakosta Indonesia, ISSN 2797-7676 (online), 2797$717 x$ (print) $\mid 14$ 
janji tentang akan adanya natal yang diperingati sebagai hari kelahiran Tuhan Yesus di Perjanjian Lama semisal dalam pembahasan keturunan perempuan yang akan meremukan kepala ular di Kejadian 3, nubuat Natan tentang keluarga, kerajaan, dan tahta Daud akan kokoh selamanya di 2 Samuel 7, ide natal lainnya dalam nubuat Yesaya maupun Mikha juga gambaran natal pertama dalam Injil. Kajian literatur peneliti gunakan untuk mendapatkan penguatan dari wacana-wacana yang peneliti bangun baik dalam Alkitab dan kisah natal maupun ketika membedah sudut pandang kaum Pentakosta tentang natal. Literatur yang digunakan bersumber dari buku semisal buku karangan French F Arrington berjudul Doktrin Kristen Perspektif Pentakosta dan juga dari artikel jurnal karya Wolfgang Vondey, Amos Yong, Peter Althouse, dan lain sebagainya yang pada intinya memiliki relevansi dengan topik yang sedang peneliti bahas.

\section{HASIL DAN PEMBAHASAN}

\section{Alkitab dan Kisah Natal}

Natal adalah kisah yang berasal dari Alkitab dan sudah mengakar kuat dalam kehidupan iman orang percaya berbagai jaman. ${ }^{11}$ Walaupun pada masa kini kisah natal telah menjadi komsumsi publik semisal banyaknya ornamen natal diberbagai tempat, lusinan produk media elektronik yang rilis setiap musim natal, dan berbagai produk lainnya yang bernuansa natal yang erat dimata publik namun dikalangan orang percaya kisah natal tetap memiliki nilai tradisi iman maupun budaya yang tetap mengetarkan hati sanubari. Ide awal natal sendiri sudah mulai nampak di Kejadian 3 dalam peristiwa Allah mendatangi manusia setelah kejatuhannya dimana pada peristiwa ini Allah begitu marah dan mengutuk baik manusia maupun ular yang waktu itu dipakai oleh si jahat untuk memuluskan rencananya menjatuhkan yang dikasihi Allah. ${ }^{12}$ Hawa terperdaya bujuk rayu ular, Adam dalam perasaan penuh cinta dengan istri akhirnya kehilangan akal sehat sehingga mengikuti saran istrinya untuk memakan buah terlarang itu juga. Dampak dari peristiwa ini tentunya membuat Allah marah. Adam dan Hawa telah menukar kebaikan Tuhan dengan dusta si jahat melalui kelicikan mulut ular.

\footnotetext{
${ }^{11}$ Kurt M. Simmons, "JOURNAL OF THE EVANGELICAL THEOLOGICAL SOCIETY," JOURNAL OF THE EVANGELICAL THEOLOGICAL SOCIETY 58, no. 2 (2015): 299-234, https://www.etsjets.org/files/JETS-PDFs/58/58-2/JETS_58-2_299-324_Simmons.pdf.

12 Kosma Manurung, “Taurat Dan Nubuat Palsu: Kajian Sudut Pandang Taurat Terhadap Nubuat Palsu," Jurnal Teologi Berita Hidup 2, no. 2 (March 31, 2020): 94-109, accessed February 23, 2021, http://www.stt-tawangmangu.ac.id/e-journal/index.php/fidei/article/view/4.
} 
Allah dalam marah-Nya pun masih dipenuhi kasih yang besar terhadap keberlangsungan jangka panjang manusia dalam peradaban mereka di muka bumi ini. ${ }^{13}$ Hal ini terlihat bagaimana Allah menawarkan solusi yang bisa memulihkan segala yang sudah dirusak oleh si jahat di taman Eden dengan menyatakan bahwa keturunan perempuan itu akan meremukan kepada ular. Artinya dari awal Alkitab sudah memastikan bahwa Allah sudah punya rencana penebusan untuk membawa manusia kembali dalam persekutuan ilahi dengan-Nya. Roy B. Zuck dalam bukunya A Biblical Teology Of The Old Testament pun berpandangan terkait hal ini yaitu penebusan Allah adalah salah satu dari lima topik yang paling sering muncul di Perjanjian Lama dan ke empat topik lainnya manusia, dosa, hubungan ikat janji, dan pemerintahan Mesias. ${ }^{14}$

Ide natal lainnya bisa dilihat dari kisah nubuat yang diucapkan oleh nabi Natan kepada Daud dalam 2 Samuel 7, peristiwa ini terjadi menurut kronologisnya setelah raja Daud memindahkan tabut Tuhan dari rumah Obed Edom orang Gat itu ke Yerusalem dimana Daud sudah mempersiapkan tempat untuk tabut Tuhan. Kerajaan sudah aman, Daud sudah tinggal tenang karena semua kerajaan disekitarnya tidak ada yang berani terhadap Daud bahkan menaruh rasa rohmat, raja Daud dalam kemapanannya melihat bahwa tabut Tuhan hanya tinggal dikemah sementara Daud tinggal ditempat yang begitu mewah. Bagi Daud sepertinya hal ini kurang pas, seharusnya tabut Tuhan juga tinggal ditempat yang baik bahkan lebih baik dari tempat tinggalnya. Kasih yang mengalir dari hati Daud ini dibaca oleh Allah dan melalui nabi Natan Allah mengkomfirmasi dan memberikan penjelasan kepada Daud bahwa Allah tidak pernah menuntut manusia untuk membuatkan tempat bagi-Nya. Namun bukan berarti Allah menolak ide ataupun keinginan raja Daud, bahkan Allah menyetujui-Nya tapi bukan Daud yang akan membangun rumah Tuhan melainkan putranya.

Pesan Allah melalui nabi Natan ini juga membicarakan sesuatu yang begitu jauh kedepan bahkan berbicara tentang kekekalan. Dimana Allah berjanji melalui Natan bahwa keluarga, kerajaan, dan tahta Daud akan kokoh selamanya (2 Sam. 7:16). Mengkaji dengan mendalam maksud dari pernyataan nabi Natan dalam pembahasan ini, peneliti memandang bahwa pernyataan ini merupakan nubuatan yang terhubung dengan masa depan yang didalamnya bersifat mesianik. ${ }^{15}$ Melihat fakta dari kerajaan Daud yang pecah menjadi dua

\footnotetext{
${ }^{13}$ Hari Sulastio, "Keselamatan Karena Kasih Karunia Menurut Efesus 2:1-10," ANTUSIAS Jurnal Teologi dan Pelayanan 6, no. 1 (2020): 62-75, https://www.sttintheos.ac.id/ejournal/index.php/antusias/article/view/307.

${ }^{14}$ Roy B. Zuck, A Biblical Teology Of The Old Testament (Malang: Gandum Mas, 2015), 11.

${ }^{15}$ Robert M. Grant and David Tracy, Sejarah Singkat Penafsiran Alkitab (Jakarta: BPK Gunung Mulia, 2015), 74.
}

Copyright(C2021; Ritornera - Jurnal Teologi Pentakosta Indonesia, ISSN 2797-7676 (online), $2797-$ $717 x$ (print) $\mid 16$ 
kerajaan yaitu kerajaan Israel disebelah utara dan kerajaan Yehuda serta kedua kerajaan itu pun hancur nyaris tidak berbekas bahkan jauh sebelum jaman Perjanjian Baru. Sejarah mencatat bahwa kerajaan Israel di sebelah Utara diserang dan dihancurkan Asyur tahun 722 SM dan kerajaan Yehuda juga hancur oleh Babel dibawah komando tertinggi Nebukadnezar tahun 586 SM. ${ }^{16}$ Perjanjian Baru kemudian mengkonfirmasi bahwa silsilah Tuhan Yesus berasal dari keluarga ataupun keturunan Daud (Mat. 1). Jelas sudah bahwa nubuat yang diucapkan nabi Natan tentang kokohnya tahta Daud mengacu pada pribadi Yesus yang lahir di Betlehem atau kota Daud yang Alkitab gambarkan sebagai Allah yang turun untuk menebus umat manusia yang pemerintahan-Nya dari kekal sampai kekal.

Ide akan adanya hari natal selanjutnya adalah dalam kitab Yesaya. Terkait nabi Yesaya, Hassell Bulock dalam bukunya Kitab Nabi-Nabi Perjanjian Lama menyebut Yesaya sebagai nabi yang tiada tandingannya. ${ }^{17}$ Leon J. Wood pun sepakat akan hal ini dan menyatakan bahwa Yesaya adalah nabinya para nabi karena dua alasan yaitu karena kecakapannya dan karena banyaknya nubuat mesianik yang dipercayakan Allah melalui Yesaya di Perjanjian Lama lebih banyak dari pada siapapun juga. ${ }^{18}$ Misalkan saja apa yang Yesaya nyatakan dalam Yesaya 9:5 bahwa seorang putra telah diberikan dan lambang pemerintahan ada padanya, namanya disebut orang penasihat ajaib, Allah yang perkasa, Bapa yang kekal, dan raja damai ataupun nubuat Yesaya tentang hamba Tuhan dalam Yesaya 42 dan bagian lainnya dari kitab ini yang membahas tentang Mesias. Rasanya tidaklah berlebihan apabila Bullock dan Wood teolog menyematkan penghargaan yang tinggi kepada nabi Yesaya.

Yesaya dengan yakin menyatakan bahwa seorang putra telah diberikan. Kata

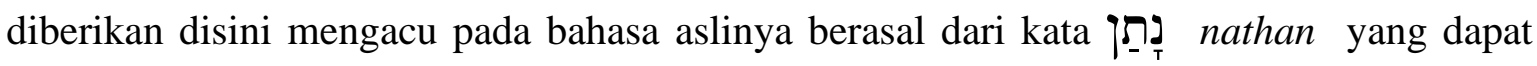
dimaknai juga sebagai sebuah ketetapan yang lahir dengan dedikasi untuk memberikan anugerah. Terkait hal ini, Leon J. Wood juga menyepakati bahwa dalam pandangan Yesaya, Tuhan memberikan keselamatan kepada umat-Nya hanya oleh kasih karunia-Nya saja. ${ }^{19}$ Artinya jelas bahwa dalam pandangan Yesaya putra ini diberikan bukan sebagai anugerah yang sudah ditetapkan. Lebih lanjut Yesaya melihat anak ini bukanlah anak sembarangan karena lambang pemerintahan ada dibahunya. Artinya anak ini memiliki otoritas yang tinggi

\footnotetext{
${ }^{16}$ Robert B. Coote, Sejarah Deuteronomistik (Jakarta: BPK Gunung Mulia, 2014), 1.

${ }^{17}$ C. Hassell Bullock, Kitab Nabi-Nabi Perjanjian Lama (Malang: Gandum Mas, 2014), 169.

${ }^{18}$ Leon J. Wood, The Prophets of Israel (Malang: Gandum Mas, 2005), 436-437.

${ }^{19}$ Ibid, 440.
} 
besar kata Yesaya, bahkan Ia membuat damai sejahtera tidak berkesudahan diatas tahta Daud dengan keadilan dan kebenaran sampai selama-lamanya (Yes. 9:6).

Ide tentang natal lainnya dalam Perjanjian Lama juga bisa dilihat dalam kitab Mikha, bahkan ada lagu natal tempo dulu yang sering berkumandang disaat natal yang isinya menyatakan cerita kelahiran Tuhan Yesus ada dalam tulisan nabi Mikha. Bullock sendiri berkesimpulan bahwa pesan tentang pengharapan dan janji menandai seluruh kitab Mikha. ${ }^{20}$ Bisa dibilang Mikha hidup pada zaman yang sama dengan Yesaya dan ada kemiripan point penting dalam pengajaran mereka, baik Mikha maupun Yesaya sama-sama memberikan tekanan utama pada dosa dan hukuman tertentu apabila umat pilihan tidak bertobat dari dosa mereka. ${ }^{21}$ Mikha hidup dalam suatu kondisi kerohanian umat Tuhan waktu itu yang sedemikian rusak akibat pemimpin yang berpaling dari jalan-jalan Tuhan ditambah lagi pengaruh nabi palsu dengan banyaknya pesan ilahi yang bukan berasal dari Allah Israel yang celakanya dipercayai oleh umat Tuhan.

Pesan Tuhan melalui nabi Mikha seperti angin segar yang memberikan harapan bagi umat akan adanya sebuah zaman baru yang akan diperintah oleh raja yang yang permulaannya sejah purbakala (Mi. 5:1). Ada sebuah kisah di Perjanjian Baru yang berkaitan langsung dengan nubuatan dalam Mikha 5: 1 ini yaitu pada waktu orang Majus datang menghadap raja Herodes yang membuat Herodes terkejut, kemudian Herodes mengumpulkan semua imam dan ahli Taurat serta bertanya kepada mereka dimana Mesias akan dilahirkan, mereka menjawab Herodes di Betlehem (Mat. 2:1-12). Terkait topik tentang sang penyelamat yang akan datang ini, Wilhelm J. Wessels seorang profesor teologi dari University of South Africa menandai serta menyepakati bahwa nabi Mikha adalah nabi yang membicarakan keselamatan yang Tuhan janjikan untuk umat-Nya, lebih lanjut Wessels melihat kegigihan Mikha menghimbau umat pilihan untuk tidak berputus asa dan tetap mengandalkan Tuhan. ${ }^{22}$

Lembaran Perjanjian Baru dimulai dengan kisah natal itu sendiri, jika dalam Perjanjian Lama kisah natal belum tahu kapan waktu tepatnya, dalam Perjanjian Baru waktu terjadinya natal sudah dicatat dengan tepat. Injil Matius menulis, waktu Maria ibu-Nya bertunangan dengan Yusuf, Maria mengandung dari Roh Kudus (Mat. 1:18). Melihat konteks budaya waktu itu, hal seperti ini sangat tidak mungkin terjadi dalam budaya Israel

\footnotetext{
${ }^{20}$ Bullock, Kitab Nabi-Nabi Perjanjian Lama, 140.

${ }^{21}$ Wood, The Prophets of Israel, 448.

${ }^{22}$ Wilhelm J Wessels, "Reflections on Micah, the Prophet of the Book Micah," Pharos Journal of Theology 100 (2019): 1-9, https://www.pharosjot.com/uploads/7/1/6/3/7163688/article_32_vol_100_2019_unisa.pdf.

Copyright(C2021; Ritornera - Jurnal Teologi Pentakosta Indonesia, ISSN 2797-7676 (online), 2797$717 x$ (print) $\mid 18$
} 
karena orang yang hidup di jaman itu baru akan tidur bersama setelah menikah dan kalau hal itu dilakukan serta ketahuan maka sanksi berat akan dijatuhkan. Bahkan, tidak menutup kemungkinan hukuman rajam akan diberikan karena telah menodai kesucian adat istiadat dan melanggar aturan Allah. Maria mengambil semua resiko termasuk barangkali resiko terburuk jika tunangannya menolak dan menyebarkan kehamilannya, kisah ini berlanjut dengan malaikat Tuhan menampakan diri pada Yusuf dalam mimpi dan memerintahkan supaya Yusuf mengambil Maria menjadi istrinya serta menjelaskan bahwa bayi yang dikandung Maria dari Roh Kudus dan harus menamai bayi itu Yesus.

Penulis kitab Lukas membahas kelahiran Yesus sudut pandang yang lebih sedikit mundur kebelakang dimana Lukas sang penulis menceritakan bagaimana malaikat Gabriel disuruh Allah kesebuah kota bernama Nazaret untuk bertemu seorang perawan yang bertunangan dengan Yusuf bernama Maria. Gabriel mendapatkan perintah dari Allah untuk mengatakan pada Maria bahwa Maria akan hamil dari Roh Kudus. Awalnya Maria ragu namun akhirnya Maria memilih untuk taat. Donald Guthrie menyetujui bahwa Matius dan Lukas memusatkan perhatian pada kisah kelahiran Yesus sebagai titik awal kehidupan Yesus dalam rupa manusia dan catatan kelahirannya mengambarkan bahwa Yesus hal ini. ${ }^{23}$ Sekalipun pada masa kini ada banyak yang meragukan tentang kelahiran Tuhan ataupun meragukan bahwa Tuhan lahir dari benih Roh Kudus melalui perawan Maria tapi bagi Tertulianus mewakili suara bapak gereja di jamannya meyakini benar Tuhan Yesus lahir dari perawan Maria melalui Roh Kudus. ${ }^{24}$ Sepanjang generasi iman Kristen terus bersaksi bahwa Tuhan yang oleh karena kasih-Nya turun kedunia lahir dikandang domba di Betlehem kota Daud.

\section{Arti Natal dalam Bingkai Spritualitas Pentakosta}

Monte Lee Rice yang dikenal sebagai seorang teolog Pentakosta menyatakan bahwa hari kelahiran Tuhan Yesus Kristus yang pada masa kini dikenal dan dirayakan sebagai natal merupakan hari yang mulia dan sangat indah karena merupakan penggenapan dari janji dan nubuat dalam Perjanjian Lama. ${ }^{25}$ Nubuat yang diucapkan Allah tentang keturunan wanita yang akan meremukan ular tergenapi melalui peristiwa kelahiran Tuhan. Begitu juga nubuat

${ }^{23}$ Donald Guthrie, TEOLOGI PERJANJIAN BARU 1 (Jakarta: BPK Gunung Mulia, 2015), 246.

${ }^{24}$ G. D. Dunn, "Mary's Virginity in Partu and Tertullian's Anti-Docetism in De Carne Christi Reconsidered," The Journal of Theological Studies 58, no. 2 (October 4, 2007): 467-484, accessed November 13, 2021, https://academic.oup.com/jts/article-lookup/doi/10.1093/jts/flm036.

${ }^{25}$ Monte Lee Rice, "Toward a Pentecostal Theological Aesthetic and Practice of Sacred Time," Journal of Pentecostal Theology 29, no. 1 (2020): 73-94, https://brill.com/view/journals/pent/29/1/articlep73_73.xml?rskey=JLgP8r\&result=2. 
janji Allah tentang keturunan keluarga, kerajaan, dan tahta Daud akan kokoh selamanya mendapatkan pengenapannya melalui kelahiran Tuhan Yesus. Nubuat Yesaya tentang seorang putra yang mana lambang pemerintahan ada padanya, namanya disebut orang penasihat ajaib, Allah yang perkasa, Bapa yang kekal, dan raja damai juga digenapi melalui kelahiran Tuhan Yesus. Peristiwa ini juga mengenapi nubuat nabi Mikha tentang seorang yang akan memerintah Israel yang lahir di Betlehem Efrata dan nubuat-nubuat lainnya di Perjanjian Lama. Ini artinya seandainya Tuhan waktu itu tidak lahir dikandang domba melalui perawan Maria maka dalam iman Kristen khususnya dalam pemahaman kaum Pentakosta, janji dalam Perjanjian Lama yang terkait dengan Mesias dan keselamatan tidak akan pernah tergenapi.

Kaum pentakosta juga memaknai hari natal sebagai sebuah peristiwa rekonsiliasi artinya ada hubungan yang sedang dipulihkan melalui peristiwa natal yaitu melalui kelahiran-Nya secara nyata janji pemulihan itu dimulai. Hancurnya hubungan dengan Allah yang disebabkan pelanggaran manusia karena lebih mempercayai perkataan si jahat mengalami pemulihan dengan fakta kelahiran Tuhan yang membawa damai. ${ }^{26}$ Seperti kata pengajaran Tuhan Yesus dalam ucapan bahagia bahwa Tuhan mengharapkan dimanapun orang percaya haruslah membawa damai atau menjadi pihak pendamai yang merupakan inti dari rekonsiliasi itu sendiri. Mark J. Cartledge berujar bahwa baik secara teologi maupun dalam tradisi kaum Pentakosta meyakini benar bahwa ketika memenuhi panggilan surgawi dalam dunia ini haruslah mengusahakan kehidupan yang pada intinya untuk kebaikan bersama dalam damai. ${ }^{27}$ Peter Althouse menyatakan sejak awal jemaat Pentakosta sudah diajari untuk berdoa bagi musuh-musuh mereka memberkati hidup mereka dan berdoa bagi keselamatan jiwa mereka serta dengan rendah hati menanggung segala sesuatu. ${ }^{28}$ Peristiwa natal bisa dijadikan kesempatan yang baik untuk membangun tradisi kumpul bersama dalam damai, penuh kasih, dan saling berbagi terutama berbagi serta memberkati orang-orang disekitar komunitas yang membutuhkan.

Hari natal juga dipahami kaum Pentakosta sebagai bagian yang tak terpisahkan dari misi Allah karena bagaimanapun juga kelahiran Tuhan Yesus dua ribu tahun lalu adalah bagian penting dari misi Allah untuk manusia. Seperti kata Amos Yong sang teolog ulung

${ }^{26}$ Manurung, "Taurat Dan Nubuat Palsu: Kajian Sudut Pandang Taurat Terhadap Nubuat Palsu", 94.

${ }^{27}$ Mark J. Cartledge, "Renewal Theology and the 'Common Good," Journal of Pentecostal Theology 25, no. 1 (2016): 90-106, https://brill.com/view/journals/pent/25/1/articlep90_9.xml?rskey=DmQMTa\&result=4.

${ }^{28}$ Peter Althouse, "The Ideology of Power in Early American Pentecostalism," Journal of Pentecostal Theology 13, no. 1 (2004): 97-115, https://brill.com/view/journals/pent/13/1/articlep97_6.xml?rskey=KGib6H\&result=21.

Copyright $(2021$; Ritornera - Jurnal Teologi Pentakosta Indonesia, ISSN 2797-7676 (online), 2797$717 x$ (print) $\mid 20$ 
Pentakosta menyatakan bahwa ketika seseorang masuk dalam komunitas Pentakosta maka hati dan pikirannya haruslah dipenuhi tentang misi. ${ }^{29}$ Hal yang serupa juga dikumandangkan oleh teolog Pentakosta lainnya Clark H. Pinnock yang menatakan bahwa gereja Pentakosta adalah gereja yang berorientasi pada misi. ${ }^{30}$ Momen natal adalah saat yang paling bagus untuk memberitakan kabar baik dari Tuhan dimana maksud kelahiran Tuhan adalah untuk menyelamatkan manusia dari hukuman dosa dan mengembalikan hubungan manusia dalam keharmonisan dengan Allah. Melihat bagaimana perayaan natal masa kini yang sudah menyusup ke lingkungan publik, pasar, mall, kantor pemerintahan, bahkan dunia digital, maka sangat pas apabila menggunakan momen natal ini untuk pemberitaan misi Allah. Manurung memberikan nasehat terkait hal ini yaitu selayaknya dilakukan dengan bijaksana seraya memperhatikan kearifan lokal setempat. ${ }^{31}$ Seperti kata Bob L. Jhonson Jr., teologi Pentekosta selalu berusaha untuk merelevansikan diri dengan keadaan jaman dan menyediakan konteks yang menarik untuk usaha ini. ${ }^{32}$

Hari natal merupakan sarana pemulihan Allah dari dampak dosa. Woflgang Vondey teolog Pentakosta yang juga guru besar di Birmingham University menyadari benar bahwa di daerah atau negara tertentu Pentakostalisme menjadi jalan keluar dari berbagai isu sosial semisal kemiskinan, korupsi, penindasan menuju kebebasan dan kemakmuran. ${ }^{33}$ Amos Yong menimpali bahwa terhadap kejahatan dan ketidak adilan orang percaya tidak boleh bersikap netral melainkan harus memihak dalam hal ini memihak pada yang tertindak sembari mengusahakan pembebasan baik yang tertindak maupun si penindas. ${ }^{34}$ Melalui kelahiran dalam rupa manusia Tuhan Yesus juga ingin memulihkan dampak dosa dalam kehidupan manusia. Dampak dosa disini bisa berupa kutuk kemiskinan, penderitaan, sakit penyakit, kebodohan, pertengkaran, kehancuran rumah tangga, korban perkosaan, dan

\footnotetext{
${ }^{29}$ Amos Yong, “GOING WHERE THE SPIRIT GOES: ENGAGING THE SPIRIT(S) IN J.C. MA'S PNEUMATOLOGICAL MISSIOLOGY,” Journal of Pentecostal Theology 10, no. 2 (2002): 110 128, https://brill.com/view/journals/pent/10/2/article-p110_8.xml?rskey=0jUtS1\&result=23.

${ }^{30}$ Clark H. Pinnock, "CHURCH IN THE POWER OF THE HOLY SPIRIT: THE PROMISE OF PENTECOSTAL ECCLESIOLOGY,” Journal of Pentecostal Theology 14, no. 2 (2006): 147-165, https://brill.com/view/journals/pent/14/2/article-p147_1.xml?rskey=sUcq7B\&result=6.

${ }^{31}$ Kosma Manurung, "Efektivitas Misi Penginjilan Dalam Meningkatkan Pertumbuhan Gereja," DUNAMIS: Jurnal Teologi dan Pendidikan Kristiani 4, no. 2 (April 6, 2020): 225-233.

${ }^{32}$ Bob L Johnson Jr, "De-Constructing and Re-Constructing the Institutional Church Toward a Theology of Spirit-Sensitive Change," Journal of Pentecostal Theology 23, no. 1 (2014): 105-128, https://brill.com/view/journals/pent/23/1/article-p105_10.xml?rskey=4jM92q\&result=4.

${ }^{33}$ Wolfgang Vondey, "The Impact of Culture and Social Justice on Christian Formation in Pentecostalism," Journal of Pentecostal Theology 24, no. 2 (2015): 201-216, https://brill.com/view/journals/pent/24/2/article-p201_7.xml?rskey=opXBwF\&result=36.

${ }^{34}$ Amos Yong, "JUSTICE DEPRIVED, JUSTICE DEMANDED: AFROPENTECOSTALISMS AND THE TASK OF WORLD PENTECOSTAL THEOLOGY TODAY," Journal of Pentecostal Theology 15, no. 1 (2006): 127-147, https://brill.com/view/journals/pent/15/1/articlep127_6.xml?rskey=wiQSae\&result=6.
} 
banyak tindakan jahat lainnya. Orang yang mengalami hal itu pastilah dalam kondisi sangat ingin mengalami pemulihan dan dalam pandangan kaum Pentaksota orang percaya harus bertindak aktif dalam menanggulangi dampak dosa karena pesan natal adalah kabar kesukaan bagi dunia dimana melaluinya menjadi sarana pemulihan Allah dari dampak dosa.

\section{KESIMPULAN}

Natal dimasa kini sudah menjadi perayaan yang bersifat universal bukan lagi secara eksklusif dimiliki oleh orang Kristen. Lihat saja menjelang natal semua tempat keramaian, mall, bandara, pusat perbelanjaan, dan kantor pemerintahan merias dirinya dengan balutan semangat natal. Namun, tidak semua yang merayakan natal memahami pesan utuh yang terkandung dalam kisah natal itu. Berdasarkan hasil penelitian ini kaum Pentakosta melihat natal sebagai kisah yang berisikan pengenapan janji Allah. Perjanjian Lama mencatat dengan teliti berkali-kali Allah membicarakan tentang akan lahirnya Sang Juruslamat semisal nubuatan tentang keturunan wanita yang akan meremukan kepada ular di kitab Kejadian 3, nubuat Natan tentang kokohnya kerajaan dan keluarga Daud di 2 Samuel 7, nubuat Yeremia tentang seorang putra yang lambang pemerintahan ada dibahunya dan namanya disebut orang penasihan ajaib, Allah yang perkasa, Bapa yang kekal, raja Damai maupun nubuat Mikha tentang seorang penguasa yang lahir di Betlehem serta banyak nubuat lainnya. Natal membawa rekonsiliasi ilahi baik antara Allah dan manusia, sesama manusia, sesama orang percaya, maupun ditengah keluarga. Kaum Pentakosta merupakan kaum yang misi sudah begitu merasuk dalam cara berpikirnya. Artinya bagi kaum Pentaksota natal tidak terlepas dari misi ilahi Allah yang dalam perayaan natal orang percaya masa kini bisa menggunakan momen ini untuk pemberitaan Kabar Baik. Natal juga bisa menjadi sarana yang Allah gunakan untuk memulihkan dampak dosa.

\section{REFERENSI}

Althouse, Peter. "The Ideology of Power in Early American Pentecostalism." Journal of Pentecostal Theology 13, no. 1 (2004): 97-115. https://brill.com/view/journals/pent/13/1/article-p97_6.xml?rskey=KGib6H\&result=21.

Arrington, French L. DOKTRIN KRISTEN PERSPEKTIF PENTAKOSTA. Yogyakarta: ANDI Offset, 2020.

B. Coote, Robert. Sejarah Deuteronomistik. Jakarta: BPK Gunung Mulia, 2014.

Bullock, C. Hassell. Kitab Nabi-Nabi Perjanjian Lama. Malang: Gandum Mas, 2014.

Cartledge, Mark J. "Renewal Theology and the 'Common Good.'” Journal of Pentecostal Theology 25, no. 1 (2016): 90-106. https://brill.com/view/journals/pent/25/1/articlep90_9.xml?rskey=DmQMTa\&result=4.

Dunn, G. D. "Mary's Virginity in Partu and Tertullian's Anti-Docetism in De Carne Christi Reconsidered." The Journal of Theological Studies 58, no. 2 (October 4, 2007): 467-

Copyright(C2021; Ritornera - Jurnal Teologi Pentakosta Indonesia, ISSN 2797-7676 (online), 2797$717 x$ (print) $\mid 22$ 
484. Accessed November 13, 2021. https://academic.oup.com/jts/articlelookup/doi/10.1093/jts/flm036.

Grant, Robert M., and David Tracy. Sejarah Singkat Penafsiran Alkitab. Jakarta: BPK Gunung Mulia, 2015.

Guthrie, Donald. PENGANTAR PERJANJIAN BARU 1. Jakarta: BPK Gunung Mulia, 2015. . TEOLOGI PERJANJIAN BARU 1. Jakarta: BPK Gunung Mulia, 2015.

Johnson Jr, Bob L. "De-Constructing and Re-Constructing the Institutional Church Toward a Theology of Spirit-Sensitive Change." Journal of Pentecostal Theology 23, no. 1 (2014): $\quad 105-128 . \quad$ https://brill.com/view/journals/pent/23/1/articlep105_10.xml?rskey=4jM92q\&result=4.

Luludova, Elena M. "Christmas and Christmastide in the Interpretation of Russian Writers of the XVIII-XX Centuries." Space and Culture, India 6, no. 4 (December 23, 2018): 93-101. Accessed November 10, 2021. https://doi.org/10.20896/saci.v6i4.379.

Manurung, Kosma. "ALKITAB DAN HUBUNGAN PERTEMANAN KAJIAN TEOLOGI PENTAKOSTA MEMAKNAI HUBUNGAN PERTEMANAN DALAM ALKITAB." VOX DEI: Jurnal Teologi dan Pastoral 2, no. 1 (June 30, 2021): 2723-2751. Accessed July 8, 2021. https://jurnal.sttekumene.ac.id/index.php/VoxDei/article/view/35.

—. "Efektivitas Misi Penginjilan Dalam Meningkatkan Pertumbuhan Gereja." DUNAMIS: Jurnal Teologi dan Pendidikan Kristiani 4, no. 2 (April 6, 2020): 225-233.

_. "Taurat Dan Nubuat Palsu: Kajian Sudut Pandang Taurat Terhadap Nubuat Palsu." Jurnal Teologi Berita Hidup 2, no. 2 (March 31, 2020): 94-109. Accessed February 23, 2021. http://www.stt-tawangmangu.ac.id/e-journal/index.php/fidei/article/view/4.

Pinnock, Clark H. "CHURCH IN THE POWER OF THE HOLY SPIRIT: THE PROMISE OF PENTECOSTAL ECCLESIOLOGY.” Journal of Pentecostal Theology 14, no. 2 (2006): $\quad$ 147-165. https://brill.com/view/journals/pent/14/2/articlep147_1.xml?rskey=sUcq7B\&result=6.

Rice, Monte Lee. "Toward a Pentecostal Theological Aesthetic and Practice of Sacred Time." Journal of Pentecostal Theology 29, no. 1 (2020): 73-94. https://brill.com/view/journals/pent/29/1/article-p73_73.xml?rskey=JLgP8r\&result=2.

Runturambi, Marselino Cristian. "MAKNA TEOLOGI PERAYAAN NATAL YESUS KRISTUS." TUMOU TOU Jurnal Kristianitas, Ajaran, dan Kemasyarakatan VI, no. 1 (2019): 41-57. http://ejournal-iakn-manado.ac.id/index.php/tumoutou/article/view/79.

Salurante, Tony, Aprianus Moimau, and Filmon Berek. "Tujuan Penciptaan Sebagai Cara Memahami Keberagaman Etika Dalam Kekristenan." Jurnal Teologi Berita Hidup 3, no. 2 (March 25, 2021): 120-136. Accessed November 10, 2021. https://ejournal.sttberitahidup.ac.id/index.php/jbh/article/view/91.

Siahaan, Harls Evan R. "Karakteristik Pentakostalisme Menurut Kisah Para Rasul." DUNAMIS: Jurnal Penelitian Teologi dan Pendidikan Kristiani 2, no. 1 (November 4, 2017): 12. Accessed June 17, 2020. doi: https://doi.org/10.30648/dun.v2i1.132.

Simmons, Kurt M. "JOURNAL OF THE EVANGELICAL THEOLOGICAL SOCIETY." JOURNAL OF THE EVANGELICAL THEOLOGICAL SOCIETY 58, no. 2 (2015): 299-234. https://www.etsjets.org/files/JETS-PDFs/58/58-2/JETS_58-2_299324_Simmons.pdf.

Sulastio, Hari. "Keselamatan Karena Kasih Karunia Menurut Efesus 2:1-10." ANTUSIAS Jurnal Teologi dan Pelayanan 6, no. 1 (2020): 62-75. https://www.sttintheos.ac.id/ejournal/index.php/antusias/article/view/307.

Sutoyo, Daniel. “Analisis Historis Terhadap Teologi Gerakan Pentakostalisme.” DUNAMIS: Jurnal Teologi dan Pendidikan Kristiani 2, no. 2 (April 23, 2018): 167. Accessed June 17, 2020. doi: https://doi.org/10.30648/dun.v2i2.171.

Vondey, Wolfgang. "The Impact of Culture and Social Justice on Christian Formation in 
Pentecostalism." Journal of Pentecostal Theology 24, no. 2 (2015): 201-216. https://brill.com/view/journals/pent/24/2/articlep201_7.xml?rskey $=$ opXBwF\&result $=36$.

Wessels, Wilhelm J. "Reflections on Micah, the Prophet of the Book Micah." Pharos Journal of Theology $100 \quad$ (2019): $1-9$. https://www.pharosjot.com/uploads/7/1/6/3/7163688/article_32_vol_100_2019_unisa. pdf.

Wood, Leon J. The Prophets of Israel. Malang: Gandum Mas, 2005.

Yong, Amos. "GOING WHERE THE SPIRIT GOES: ENGAGING THE SPIRIT(S) IN J.C. MA'S PNEUMATOLOGICAL MISSIOLOGY." Journal of Pentecostal Theology 10, no. 2 (2002): 110-128. https://brill.com/view/journals/pent/10/2/articlep110_8.xml?rskey=0jUtS1\&result=23.

-. "JUSTICE DEPRIVED, JUSTICE DEMANDED: AFROPENTECOSTALISMS AND THE TASK OF WORLD PENTECOSTAL THEOLOGY TODAY." Journal of
Pentecostal
Theology
15 ,
no.
(2006):
$127-147$.

https://brill.com/view/journals/pent/15/1/article-

p127_6.xml?rskey=wiQSae\&result=6.

Zaluchu, Sonny. "Penderitaan Kristus Sebagai Wujud Solidaritas Allah Kepada Manusia." DUNAMIS: Jurnal Penelitian Teologi dan Pendidikan Kristiani 2, no. 1 (November 4, 2017): 61. Accessed November 17, 2020. http://www.sttintheos.ac.id/ejournal/index.php/dunamis.

Zaluchu, Sonny Eli. "Strategi Penelitian Kualitatif Dan Kuantitatif Di Dalam Penelitian Agama." Evangelikal: Jurnal Teologi Injili dan Pembinaan Warga Jemaat 4, no. 1 (2020): 28-38.

Zuck, Roy B. A Biblical Teology Of The Old Testament. Malang: Gandum Mas, 2015.

0.46445/ejti.v4i1.167. 